\title{
Customers' Online Purchase Intention: Applying Extended Theory of Planned Behaviour (TPB) Model
}

\author{
Mohamed Rameez ${ }^{1} \quad$ Dushyantha Kulathunga ${ }^{2 *}$ \\ 1.Faculty of Graduate Studies, University of Sri Jayewardenepura, Nugegoda, Sri Lanka \\ 2.Department of Information Technology, University of Sri Jayewardenepura, Nugegoda, Sri Lanka
}

\begin{abstract}
This research extended the theory of planned behaviour (TPB) with familiarity, trust, and perceived risk to examine the consumers' online purchase intention in Sri Lanka. Data were collected from 250 postgraduate students enrolled in eight universities and higher education institutes in Sri Lanka. Structural equation modelling confirmed the role of trust and familiarity as antecedents to customer intention. However, contrary to the expectations, perceived risk was not identified as a key determinant of customer intention. Further, among the three classical variables (attitude, subjective norm, and perceived behaviour control) of the TPB model, only attitude had a significant effect on customer intention. Amongst all the factors, trust was identified as the most influencing factor on customer intention. The extended TPB model could satisfactorily predict the customer intention with up to $46 \%$ variation of the customer intention.
\end{abstract}

Keywords: Theory of planned behaviour (TPB), Ecommerce, Customer intention, Online purchase intention, Online behaviour

DOI: $10.7176 / \mathrm{IKM} / 9-10-04$

Publication date: November $30^{\text {th }} 2019$

\section{Introduction}

The Internet is rapidly becoming fast growing retailing platform in the world (Cheng, Lam and Yeung, 2006). It connects a large number of customers, institutions and suppliers for virtual transaction (Pavlou and Chai, 2002). E-commerce enables consumers to purchase products and services online using Internet technologies and associated infrastructure (Olson and Olson, 2000). Online transaction combines new technology and new behavioural pattern into new way of product and service offering by communicating necessary information with wide across customer segments via electronic channels of virtual stores (Dennis et al., 2008).

Globalization and universal nature of the Internet has enabled people to engage in online transactions (Pavlou and Chai, 2002) in both developed as well as in developing countries. Online retail sale in the US is astonishing and continues to grow at a rapid rate by outperforming sales growth at traditional stores (Forrester Research, 2013). As consumer wallet share gradually shifts towards the web retailers, online sales has become a critical part of the retail economy of many European countries (Forrester Research, 2013). Impressive growth in B2C ecommerce sales in Asia-Pacific region is expected to overtake North America to become world's number one market for B2C ecommerce in coming years (Asia Briefing, 2014).

In post war Sri Lanka, the emerging trend in market dynamism is changing the consumer consumption pattern and processing of business transaction. The Internet is affecting unprecedented changes in business conduct in Sri Lanka. Locally more and more organizations are going for online while maintaining their offline business as well. Believing that e-commerce can foster economic development, the government of Sri Lanka has also taken numerous initiatives in improving ICT infrastructure and computer literacy among the general public. In Sri Lanka, e- commerce segment has been expanding at a growth of 34\% for year on year, as at July 2018 (DailyNews, 26.11.2018)

Unlike traditional stores, transaction over the Internet has notable differences such as the intangibility, impersonality, distance nature of the online environment, easiness in information collection, processing and sharing by various parties and implicit uncertainty associated with internet infrastructure (Pavlou and Chai, 2002). Overall, the spatial and temporal separation among consumers and web retailers increases uncertainty and reduces consumer perceptions of control over their online transactions, imposing a barrier to e-commerce adoption (Pavlou and Chai, 2002).

\subsection{Problem statement}

Amazing growth in e-commerce worldwide is facilitating and rapidly transforming conventional retailing in to a progressively growing online trading platform in Sri Lanka. Online transactions combine new technology and new consumer behaviourism in to new way of product and service delivery through electronic channel. The emerging market trend is subsequently changing the consumer consumption pattern and their business transaction process.

\footnotetext{
${ }^{1}$ Mohamed Rameez was a postgraduate student at the time of doing this research.
} 
The Internet has originally been developed as a communication platform and later it has been transformed in to a trading platform (Chellappa and Pavlou, 2002). This transformation has demanded new technologies and changes in consumer behaviourism. ICT infrastructure and Internet literacy (Li, Kuo, and Russell, 1999) and availability of credible payment mechanism such as credit cards (Oxley and Yeung, 2001) are extremely important for success of e-commerce activity.

Sri Lanka is witnessing tremendous development in ICT infrastructure (Central Bank report, 2012). Such developments are enabling and improving the Internet literacy among the people in general and professionals in particular. The usage of electronic retail payment systems such as payment cards, mobile phone based payments and Internet payment systems have shown a significant growth in recent years due to customer convenience and efficiency provided by such payment systems (Central Bank report, 2012). Online search queries for all categories from beauty to automotive to telecom have increased by 25 times in Sri Lanka (Hathiramani, 2013). People who seek access to the Internet very often are more likely to engage in online transactions even when online retailing is something new (Liao and Cheung, 2000). However, the explicit social manifestation in the Internet hasn't been substantially transformed into an online trading activity in the Island. As a result, e-commerce market in Sri Lanka currently stands at just US\$ 40 million in comparison with conventional retailing of US\$ 10 billion (LBO, 2017). Further, only 17 percent in Sri Lanka complete the full transaction of an online purchase which include the steps: search, order, payment and delivery (Economynext, 2019).

Amidst the promising developments of ICT infrastructure, Internet literacy, and usage of credit cards; limited information is available about consumer decision making over the Internet in Sri Lanka. Apart from that, the uneven distribution of ICT infrastructure greatly limits the generalization of available research findings. Further, very little research has been done in the Island in understanding how consumer transactional intention is influenced by social demographic, psychological, and economic factors. This socioeconomic reality, demands a new conceptualization of online consumer behaviourism to better understand what drives the online transactional decisions. Despite the significant development in ICT infrastructure, Internet penetration, computer literacy and electronic payment system, it is not certain what holds back customers from being engaged with online transactions in Sri Lanka. Based on the above understanding, the study formulates the following research question:

"What are the factors that influence the intention to perform online transactions among professionals in Sri Lanka"?

\subsection{Objectives of the study}

Based on the research question specified above, the researchers developed two objectives for this study, as specified below.

- To identify the factors influencing online purchase intention

- To determine the relationships between identified factors and online purchase intention

\section{Theoretical Background}

A review of literature reveals that the Theory of Planned Behaviour (TPB), Theory of Reasoned Action (TRA), and Technology Acceptance Model (TAM) are theories that have been used extensively in examining the adoption of information technology.

\subsection{Theory of Planned Behaviour (TPB)}

TPB can be identified as the most comprehensive theory in social psychology in determining behavioural intention. The TPB proposes a model about how human action is guided (Ajzen, 1991). The TPB emphasizes that specific salient beliefs influence individual's behavioural intention and subsequent behaviour (Ajzen, 1991). In the TPB model, a person's intention is a function of three basic determinants: attitudes (ATD), subjective norms (SN) and perceived behaviour control (PBC) (Ajzen, 1985).

The predictive power of this theoretical model has been established in a large number of online purchasing behaviour research (Battacherjee, 2000; Jarvenpaa and Todd, 1997; Khalifa and Limayem, 2003; Pavlou and Chai 2002; George, 2004). Importantly TPB provides robust theoretical basis for testing variables other than classical variables. Accordingly, some of the variables that are inherent to online transaction such as 'trust' (Pavlou and Chai, 2002; George, 2004; Dennis at el., 2008; Wen, 2009; Kamarulzaman, 2007), 'past experience' (Dennis at el., 2008; Wi-Suk Kwon, 2009), 'privacy' (George, 2004), 'perceived risk' (Kamarulzaman, 2007; Lee, 2009; Kwon, 2009), 'perceived benefit' (Lee, 2009) and 'familiarity' (Gefen, 2000; Kim, Ferrin and Rao, 2008) have been studied frequently, along with the TPB model.

\subsection{Theory of Reasoned Action (TRA)}

Theory of Reasoned Action (Fishbein and Ajzen, 1975, cited in Pavlou, 2003) is used to understand the consumer intention and subsequent purchasing behaviour. In the TRA model, a person's intention is a function of two determinants namely; attitude and subjective norm. The first determinant, attitude toward behaviour, reflects a person's beliefs that the behaviour leads to certain outcomes and evaluation of those outcomes as favorable or 
unfavorable. The second determinant is subjective norm, which reflects the perceived expectations from others (such as family, friends, neighbors, co-workers) that influence a user to perform a particular behaviour (Ajzen, 1991).

\subsection{Technology Acceptance Model (TAM)}

Technology Acceptance Model developed by Davis et al. (1989) is also widely used in explaining technology adoption by consumers, institutions and nation as a whole. TAM is also an extension of TRA model. In the TAM model, two determinants namely; perceived usefulness (PU) and perceived ease of use (PEOU) have been viewed as predictors of intention (Davis, 1989). The perceived usefulness is defined as the degree to which a "person believes that using the system will enhance his or her performance" (Davis, 1989). The perceived ease of use is defined as the degree to which a "person believes that using the system will be free of mental effort" (Davis. 1989). According to TAM, both key determinants affect a person's attitude and that attitude determines the behavioural intention and latter leads to actual behaviour. Further, attitude and PU predict person's behavioural intention. PU is also influenced by PEOU and subsequently it could indirectly affect the behavioural intention via PU.

\section{Methodology}

\subsection{Conceptual Framework}

TPB provides a strong theoretical basis for testing a number of additional variables in relation to behavioural intention (George, 2004). Accordingly, in this study there are three new variables namely, familiarity, trust and perceived risk which have been integrated in to the TPB framework. Those variables were initially derived from an elicitation study and its relevance further confirmed through experts' opinion and vigorous literature review. According to Pavlou and Chai (2002) the integrated new variables must be operationally consistent with variables of classical TPB. Therefore, it is necessary to justify the operational compatibility of integrated variables of familiarity, trust and perceived risk with TBP model's classical variables of attitude, subjective norm and perceived behaviour control. The integrated variables of familiarity (Kim. Ferrin and Rao, 2008), trust and perceived risk (Pavlou and Cliai. 2002) in a web retailer deal with a single transaction decision in a given context at a given time (Pavlou and Chai 2002). Similarly, ATD, SN and PBC also deal with a single transaction decision in a given system at a single point in time (Pavlou and Chai. 2002). Further, variables of trust and perceived risk, and familiarity are at the same level of abstraction as ATD, SN and PBC (Pavlou and Chai. 2002). The three classical variables have been directed at measuring general beliefs without specifying the precise details of an internet system (Pavlou and Chai. 2002). Likewise, familiarity, trust and perceived risk in this study were also directed in measuring general perceptions of web retailers' features regardless of precise details of particular web retailer (Pavlou and Chai, 2002).

Further, integrated variables of trust and perceived risk as well as familiarity are very relative terms. These variables are relative to the observer and therefore it is a subjective thing. That means the interpretation of those variables depends upon the person as well as on the situation (Pavlou and Chai, 2002). Similarly, ATD, SN and PBC, too deal with observers' subjective assessment of those variables. That means the interpretation of those variables is influenced by a wide variety of cultural, personal and situational factors (Ajzen and Fishbein, 1980). For the purpose of determining its impact on intention, those three new variables were identified not only as relevant to the study but also as compatible with existing TPB variables. Thus, it can be assured that the three new variables introduced in to the conceptual framework are compatible with ATD, SN and PBC, which were deemed prerequisites when extending the TPB model as asserted by Ajzen and Fishbein (1980). Accordingly, the conceptual framework depicted in Figure 1 was developed for this study. 


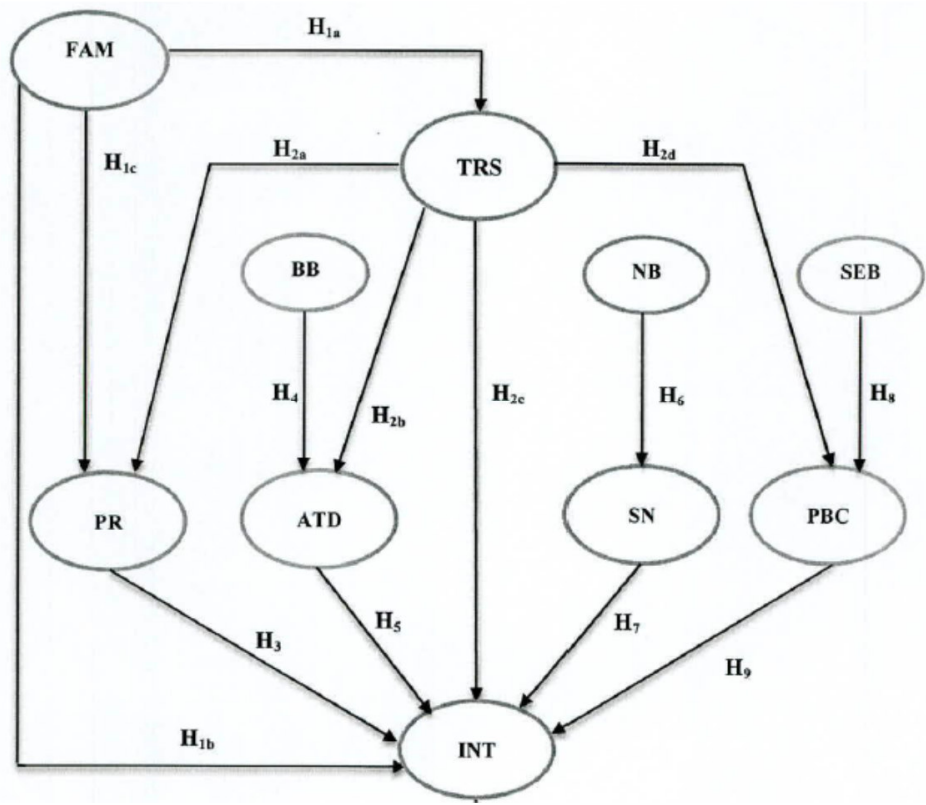

Figure 1: Conceptual Framework

Note:

$$
\begin{aligned}
& \text { ATD = Attitude } \\
& \text { BB = Behaviour Belief } \\
& \text { TRS = Trust } \\
& \text { FAM = Familiarity }
\end{aligned}
$$

$$
\begin{aligned}
& \mathrm{SN}=\text { Subjective Norm } \\
& \mathrm{NB}=\text { Normative Belief } \\
& \mathrm{PR}=\text { Perceived Risk }
\end{aligned}
$$

$$
\begin{aligned}
& \text { PBC }=\text { Perceived Behaviour Control } \\
& \text { SEB }=\text { Self Efficacy Belief } \\
& \text { INT }=\text { Intention to purchase online }
\end{aligned}
$$

\subsection{Hypotheses Development}

\subsubsection{Familiarity with Trust, Intention and Perceived Risk}

The influence of familiarity on intention, trust and perceived risk has been empirically established by a number of studies. Gefen (2000) and Kim, Ferrin and Rao (2008) have shown that consumer familiarity with web retailer affected the consumer willingness to purchase. Gefen (2000) found that consumer trust and familiarity with a web retailer and its transaction procedure significantly influenced on inquiry, and subsequent purchase of books. Kim, Ferrin and Rao (2008) empirically tested the influence of familiarity on trust, perceived risk and purchase intention. Interestingly they have found that familiarity had a strong direct influence on trust and consumer's purchase intention. Mostafa and Elseidi (2018) found a significant and negative relationship between consumer familiarity with private label brands (PLBs) and perceived risk of the product. Thus, they supported the notion that the more the consumer is familiar with the PLB, lower is its perceived risk. Further Gefen, Karahanna and Straub (2003) have shown that among the potential and repeat customers, familiarity had a significant and positive influence on trust and intention to purchase books from a specific electronic vendor. Hence, it is important to understand the role of familiarity on trust, perceived risk and intention in the context of online transactions, particularly in Sri Lanka. Accordingly, the following three hypotheses were proposed.

Hypothesis $\mathbf{H}_{1 \mathbf{a}}$ : Consumers' familiarity with web retailer positively influences the consumers' trust.

Hypothesis $\mathbf{H}_{1 \mathbf{b}}$ : Consumers' familiarity with a web retailer positively influences the consumers' intention to perform online transactions.

Hypothesis H1c: Consumers' familiarity with a web retailer negatively influences the consumers' perceived risk.

3.2.2 Trust with Perceived Risk

In this study, researcher attempted to understand the relationship between the consumer trust and perceived risk towards performing online transaction. In the context of ecommerce, it has been found that consumer trust negatively influences on consumer's perceived risk (Thompson and Liu, 2007; Kim, Ferrin and Rao, 2008). Similarly, consumer trust on Internet store (Jarvenpaa, Tractinsky and Vitale, 2000; Heijden, Verhagen, \& Creemers, 2003; Kimery and Mccord, 2002; Pavlou 2003) reduces perceived risk of buying online. In general, trust improves the consumer's beliefs about web retailer and reduces risk involved in online transaction (Pavlou, 2003). Accordingly, the following hypothesis was proposed.

Hypothesis $\mathbf{H}_{2 \mathrm{a}}$ : Consumers' trust negatively influences the consumers' perceived risk towards online transactions 


\subsubsection{Trust with Attitude}

Among the scholars, there is general agreement that trust is related with positive feelings, beliefs, and attitudes (McKnight and Chervany, 2002). Trust on the web retailer creates positive feeling and expectation for satisfaction in online transaction (Pavlou and Chai, 2002). Accordingly, trust in the web retailer has been identified to positively influence on customer attitude towards performing online transaction (Jarvenpaa, Tractinsky and Vitale, 2000; Pavlou and Chai, 2002; Kimery and Mccord, 2002; Suh and Han, 2003; George, 2004; Thompson and Liu, 2007). Consequently, the following hypothesis was proposed.

Hypothesis $\mathbf{H}_{2 \mathrm{~b}}$ : Consumers' trust positively influences the consumers' attitude towards online transactions. 3.2.4 Trust with Intention

Consumers significantly rely on trust, in the absence of experience-based evidence with a web retailer, in performing online transactions (Gefen, Karaharina and Straub, 2003). On the other hand, trust reduces behavioural uncertainty related to the web retailers' action and provides a consumer a perception of some control over a potentially uncertain transaction (Pavlou. 2003). This sense of overall control over their online transactions positively influences consumers' purchase intentions (Pavlou, 2003). Several trust related research in ecommerce have shown that there is a significant and positive relationship between trust and intention when purchasing from a web retailer (Suh and Han, 2003: Gefen. Karahanna and Straub. 2003; Pavlou. 2003. Chen and Barnes, 2007; Roca, Garcia, \& Vega, 2008: Kim. Ferrin and Rao, 2008). Therefore, the following hypothesis was proposed.

Hypothesis H2c: Consumers' trust positively influences the consumers' intention to perform online transactions.

\subsubsection{Trust with Perceived Behaviour Control}

Trust on the web retailer increases the amount of control consumer has over the situation through having confidence on the web retailer's behavioural actions. From a TPB perspective, a belief that a web retailer will behave in accordance with consumer confident expectations is likely to increase the amount of his control over the transaction (Pavlou and Chai, 2002). Wu \& Chen (2005) found that the trust beliefs towards online tax payment system were able to increase citizen's perceived behavioural control in performing the behaviour. Hence, they identified trust as an antecedent of perceived behavioural control. Based on these arguments and findings, following hypothesis was proposed.

Hypothesis $\mathbf{H}_{2 \mathrm{~d}}$ : Consumers' trust positively influences the consumers' perceived behaviour control towards online transactions.

\subsubsection{Perceived Risk with Intention}

Pavlou (2003) claimed that beliefs about web retailers are partly determined by behavioural and environmental factors. It is expected from a consumer perspective that the perceived risk makes them decline to engage with online transactions owing to uncertain nature of e-commerce. When consumer understands that either web retailers intend to be opportunistic (Pavlou. 2003: Lee, 2009; Kim. Ferrin and Rao, 2008) or if they fear that web retailer hasn't taken adequate infrastructure related security measures (Chellapaa and Pavlou, 2002; Pavlou, 2003; Lee, 2009; Kim. Ferrin and Rao. 2008) then consumers prevent themselves from engaging in online transactions. Accordingly, the following hypothesis was proposed.

Hypothesis $\mathbf{H}_{3}$ : Consumers' perceived risk negatively influences the consumers' intention to perform online transactions.

\subsubsection{Attitude with Intention}

Attitude toward the behaviour is a person's overall evaluation of the behaviour (Ajzen, 1991). According to him, it is assumed to have two components which work together: beliefs about consequences of the behaviour (behaviour belief strength) and the corresponding positive or negative evaluation of the behaviour (outcome evaluation). He further stated, both behavioural belief strength and outcome evaluation could also serve to compute a behavioural belief composite that is assumed to determine the attitude towards behaviour (AB). Hence, specifically if the perceived advantages outweigh the perceived disadvantages in performing a behaviour, and then people are likely to form a favorable attitude towards the behaviour and vice versa (Ajzen, 1991).

In terms of online transactions, attitude is belief about online transaction and overall evaluation of the transaction activities with a web retailer. Therefore, it is likely to influence the proposed transaction activities with a retailer (Pavlou, 2002). Hence, a favorable attitude is expected to ease online transactions and reduces barriers to the adoption of ecommerce (Jarvenpaa, Tractinsky \& Saarinen, 1999; Pavlou \& Chai, 2002). Following the TPB, a favorable attitude towards online transactions with a web retailer is expected to positively influence consumer online transaction intentions. According to these arguments, following two hypotheses were proposed.

Hypothesis $\mathbf{H}_{4}$ : Consumers' behaviour belief about online transactions positively influences the consumers' attitude towards intention to perform online transactions.

Hypothesis H5: Consumers' positive attitudes towards online transactions positively influence on the consumers' intention to perform online transactions.

3.2.8 Subjective Norm with Intention

Subjective norms are a person's own estimate of the social pressure whether to perform the intended behaviour 
(Ajzen, 1991). The subjective norm is assumed to have two components which work in interaction: beliefs about how most respected other people, would like them to behave (normative belief strength) and motivation to comply with most respected other people (motivation to comply). The product of 'normative belief strength' and 'motivation to comply' is called normative belief and was identified as a determinant of subjective norm (Ajzen and Fishbein, 1980).

Based on the TPB, it is expected that subjective norm will have an influence on the intentions of consumers to engage in online transactions (Pavlou \& Chai, 2002). An individual is more likely to engage in online transactions if social expectations are that people should engage in the behaviour in question (George, 2004). Conversely, if social expectations are that people should not engage in the behaviour, then the individual should be less likely to do so. If transaction over the Internet is seen as a socially desirable behaviour, based on what important others think about it, then the individual is more likely to make online transactions. Consequently, the following two hypotheses were proposed.

Hypothesis H6: Consumers' normative beliefs about online transactions will positively influence consumers' subjective norms.

Hypothesis H7: Consumers' subjective norms will have a positive influence on the consumers' intention to perform online transactions.

3.2.9 Perceived Behaviour Control with Intention

According to George (2004), if an individual is self-confident about engaging in activities related to purchasing online, he or she should feel positive about his or her behavioural control over intention to make online transactions. George (2004) has shown that belief about self-efficacy of using the Internet act as an antecedent to the PBC and subsequently PBC influences online purchasing behaviour. Although, PBC had a smaller effect on intention in accepting e-commerce services (Bhattacherjee, 2000) in some studies, it had strong influence on intention (Taylor \& Todd, 1995; Pavlou and Chai, 2002) as well as on purchasing behaviour (Taylor and Todd, 1995) in some other studies. Based on those findings, following two hypotheses were proposed.

Hypothesis Hs: Consumers' self-efficacy beliefs in engaging online transactions positively influence on consumers' perceived behaviour control.

Hypothesis H9: Consumers' perceived behaviour control will have a positive influence on consumers' intention to perform online transactions.

\subsection{Instrument development}

The questionnaire used in this study was developed using a four stage process guided by the Theory of Planned Behaviour (Ajzen, 1991). First, an elicitation study was done to get an overview of the customers' intention and attitude towards online transactions. Second, the results of the elicitation study were utilized to develop and select appropriate questionnaire items from previous literature to measure the relevant variables. Third, a pre-test of the questionnaire was performed using 10 respondents of the selected sample. Pre-test resulted in the simplification and further improvement of the understandability of the questionnaire. Fourth, a Pilot study with 50 respondents was performed to validate the questionnaire. Thereafter, the questionnaire was finalized.

\subsection{Sample of the study}

The target sample for this study was identified as Professionals who Enrolled with Postgraduate Studies ('PEPS') in leading Universities in the Western Province of Sri Lanka. The sample consisted of both males and females between the ages of 25-55 years who had Internet connectivity at home or office and who were employed full time during the time study was conducted.

\subsection{Data analysis of the pilot study}

Data collected from the pilot survey was first analyzed using the Statistical Package for Social Science (SPSS). Exploratory Factor Analysis (EFA) with Varimax rotation was conducted to assess reliability and construct validity of the questionnaire which consisted of 45 measurement items. A cut-off point of 0.5 of factor loading was used in this study and measurements with factor loadings lesser than 0.5 were identified for deletion. This resulted in the deletion of an item from Attitude variable. Further, several cross loadings could be witnessed in relation to six variables. The researchers decided to keep only the major factor and delete the items fallen into the other factor. Those variables and the number of items deleted from each variable (specified within the bracket) are as follows. Trust (1), Perceived Risk (2), Perceived Behaviour Control (2), Self-efficacy belief (2), Behaviour Belief (2), and Normative Belief (2). Consequently, altogether twelve items were deleted, leaving only 33 items for the final study.

\subsection{Data collection of the final study}

Applying one stage cluster sampling method, data were collected by administering a Likert scale type questionnaire from a sample of 287 'PEPS' who represented eight leading Universities and higher educational institutes. Among the 'PEPS' sample, 250 responses were identified as valid and they were mainly in the age 
categories of 26-35 (74.8\%), 36-45 (21.6\%) and 46-55 (3.6\%). It included $66.4 \%$ males and 33.6\% females and all of them had Internet connectivity. The 'PEPS' sample was represented by Managers 29.2\%, Engineers 23.6\%, Sales and Marketing Managers 16.4\%, Bankers, 8.4\%, and Accountants and Financial Managers 5.6\% each respectively.

\subsection{Data Analysis of the Measurement Model}

Data analysis of the final study was carried out in two steps using the Partial Least Squares Structural Equation Modelling (PLS-SEM) technique. First, the researchers measured the reliability and construct validity (convergent validity and discriminant validity) of the questionnaire. The results are shown in Table 1. The Cronbach alpha reliability coefficients of all variables of this study were higher than the minimum cutoff score of 0.70 . Cronbach reliability coefficient of construct ranged from 0.70 to 0.91 . Also, Composite reliability of all variables were greater than 0.7 and hence were considered to be acceptable (Fornell and Larcker, 1981).

PLS confirmatory factor analysis further revealed that two items of the perceived risk variable (PR32 and PR33) have factor loadings below 0.5 (See Table 1), which are below the acceptable range (see Table 1). Hence, the researchers decided to delete those two items as well in further analysis.

Convergent validity refers to the extent to which the scale correlates positively with other measures of the same construct (Malhotra and Dash, 2009). Fornell and Larcker, (1981) asserted that convergent validity could be established when a given factor is able to extract over $50 \%$ of the variance of each measurement items. An AVE greater than 0.5 indicates that more than $50 \%$ of the variance of the measurement items can be accounted for by the constructs (Kim, Ferrin and Rao, 2008). Since AVE values of all constructs were identified as greater than 0.5 (see Table 1), the convergent validity of all variables are established.

Table: 1. Reliability and Construct Validity of Latent Variables.

\begin{tabular}{|c|c|c|c|c|c|c|c|}
\hline Construct & Item & $\begin{array}{c}\text { Factor } \\
\text { Loading }\end{array}$ & t-Stat & $A V E^{b}$ & Composite & R Square & $\begin{array}{r}\text { Cronbach's } \\
\text { Alpha }\end{array}$ \\
\hline \multirow[t]{3}{*}{ Familiarity } & FAM4 & 0.881 & 26.881 & 0.775 & 0.912 & 0.000 & 0.855 \\
\hline & FAM5 & 0.887 & 19.039 & & & & \\
\hline & FAM6 & 0.893 & 33.582 & & & & \\
\hline \multirow[t]{4}{*}{ Trust } & TRS10 & 0.836 & 23.347 & 0.700 & 0.903 & 0.150 & 0.857 \\
\hline & TRS11 & 0.853 & 23.368 & & & & \\
\hline & TRS12 & 0.818 & 21.736 & & & & \\
\hline & TRS13 & 0.839 & 21.598 & & & & \\
\hline Perceived & PR30 & 0.782 & 5.438 & 0.646 & 0.845 & 0.099 & 0.724 \\
\hline \multirow[t]{4}{*}{ Risk } & PR31 & 0.868 & 9.114 & & & & \\
\hline & PR32 & 0.463 & 1.935 & & & & \\
\hline & PR33 & 0.440 & 1.855 & & & & \\
\hline & PR34 & 0.757 & 6.241 & & & & \\
\hline \multirow[t]{3}{*}{ Attitude } & ATD17 & 0.927 & 42.287 & 0.849 & 0.944 & 0.301 & 0.911 \\
\hline & ATD18 & 0.928 & 50.485 & & & & \\
\hline & ATD19 & 0.910 & 32.089 & & & & \\
\hline Behaviour & BB1 & 0.834 & 21.496 & 0.627 & 0.834 & 0.000 & 0.703 \\
\hline \multirow{2}{*}{ Belief } & BB2 & 0.721 & 8.700 & & & & \\
\hline & BB3 & 0.816 & 18.241 & & & & \\
\hline Subjective & SN37 & 0.870 & 16.566 & 0.834 & 0.938 & 0.254 & 0.900 \\
\hline \multirow[t]{2}{*}{ Norm } & SN38 & 0.928 & 50.033 & & & & \\
\hline & SN39 & 0.941 & 68.146 & & & & \\
\hline Normative & NB1 & 0.929 & 49.798 & 0.858 & 0.924 & 0.000 & 0.834 \\
\hline Belief & NB2 & 0.924 & 51.457 & & & & \\
\hline Perceived & PBC23 & 0.889 & 34.658 & 0.636 & 0.872 & 0.416 & 0.810 \\
\hline Behaviour & PBC24 & 0.758 & 11.342 & & & & \\
\hline \multirow[t]{2}{*}{ Control } & PBC25 & 0.909 & 42.475 & & & & \\
\hline & PBC26 & 0.595 & 5.534 & & & & \\
\hline Self- & SEB1 & 0.889 & 30.760 & 0.823 & 0.933 & 0.000 & 0.892 \\
\hline Efficacy & SEB2 & 0.945 & 64.793 & & & & \\
\hline Belief & SEB3 & 0.887 & 33.921 & & & & \\
\hline \multirow[t]{3}{*}{ Intention } & INT14 & 0.901 & 38.065 & 0.812 & 0.928 & 0.459 & 0.884 \\
\hline & INT15 & 0.916 & 40.297 & & & & \\
\hline & INT16 & 0.885 & 18.515 & & & & \\
\hline
\end{tabular}

Discriminant validity refers to the extent to which a measure doesn't correlate with other constructs from 
which it is supposed to differ (Malhotra and Dash, 2009). Fornell and Larcker (1981) suggested that establishing discriminant validity require the correlation between items in any two constructs should be lower than the square root of the average variance shared by items within a construct. As shown in Table 2, the square roots of each construct's Average Variance Extracted (AVE) is larger than its correlations with other constructs (Chin, 1998). Hence, the discriminant validity of variables is established.

Table: 2: Latent Variable Correlation and Average Variance Extracted

\begin{tabular}{crrrrrrrrr}
\hline & TRS & \multicolumn{1}{c}{ PR } & BB & ATD & NB & SN & SEB & PBC & INT \\
\hline TRS & $\mathbf{0 . 8 3 6 4}$ & & & & & & & & \\
PR & -0.2987 & $\mathbf{0 . 8 0 3 8}$ & & & & & & \\
BB & 0.5181 & -0.0910 & $\mathbf{0 . 7 9 2 6}$ & & & & & \\
ATD & 0.4709 & -0.2620 & 0.4848 & $\mathbf{0 . 9 2 1 5}$ & & & & \\
NB & 0.2483 & -0.0826 & 0.3630 & 0.2449 & $\mathbf{0 . 9 2 6 2}$ & & & \\
SN & 0.4549 & -0.1918 & 0.4532 & 0.3719 & 0.5036 & $\mathbf{0 . 9 1 3 3}$ & & \\
SEB & 0.3369 & -0.0820 & 0.4832 & 0.4569 & 0.1586 & 0.2825 & $\mathbf{0 . 9 0 4 5}$ & \\
PBC & 0.2166 & 0.0646 & 0.3671 & 0.2442 & 0.0473 & 0.2255 & 0.6449 & $\mathbf{0 . 7 9 7 4}$ & $\mathbf{0 . 9 0 0 8}$ \\
INT & 0.5489 & -0.1995 & 0.5129 & 0.5214 & 0.3190 & 0.4576 & 0.4066 & 0.3321 &
\end{tabular}

Note: Diagonal elements are the square roots of AVE extracted. These values should exceed the inter-construct correlation for adequate discriminant validity.

\subsection{Analysis of the Structural Model and Discussion}

The appropriateness of the structural model was tested with PLS-SEM. The assessment of structural model included estimation of both path coefficients and R Square $\left(\mathrm{R}^{2}\right)$ values. Path coefficients in PLS are similar to standardized beta weights in regression analysis and it can be used along with $\mathrm{R}^{2}$ to assess the structural model fit (Chin, 1998).

The assessment of structural model is shown in Figure 2. The $\mathrm{R}^{2}$ for TPB variables such as ATD, SN and PBC were $0.301,0.254$ and 0.416 respectively. The $\mathrm{R}^{2}$ for Trust and Perceived risk were 0.149 and 0.099 respectively.

According to Figure 2, the variance explained for intention to perform online transaction is fairly high $\left(\mathrm{R}^{2}=\right.$ 0.46). It is well above the values found by some other researchers on performing online transaction. The variance explained for intention was 0.27 for Gefen, Karahanna and Straub (2003), 0.34 for Kim, Ferrin and Rao (2008), 0.29 for Alam. and Sayuti (2011), and 0.40 for Giampietria, Verneaub, Giudicec, Carforad, \& Fincoa (2018)

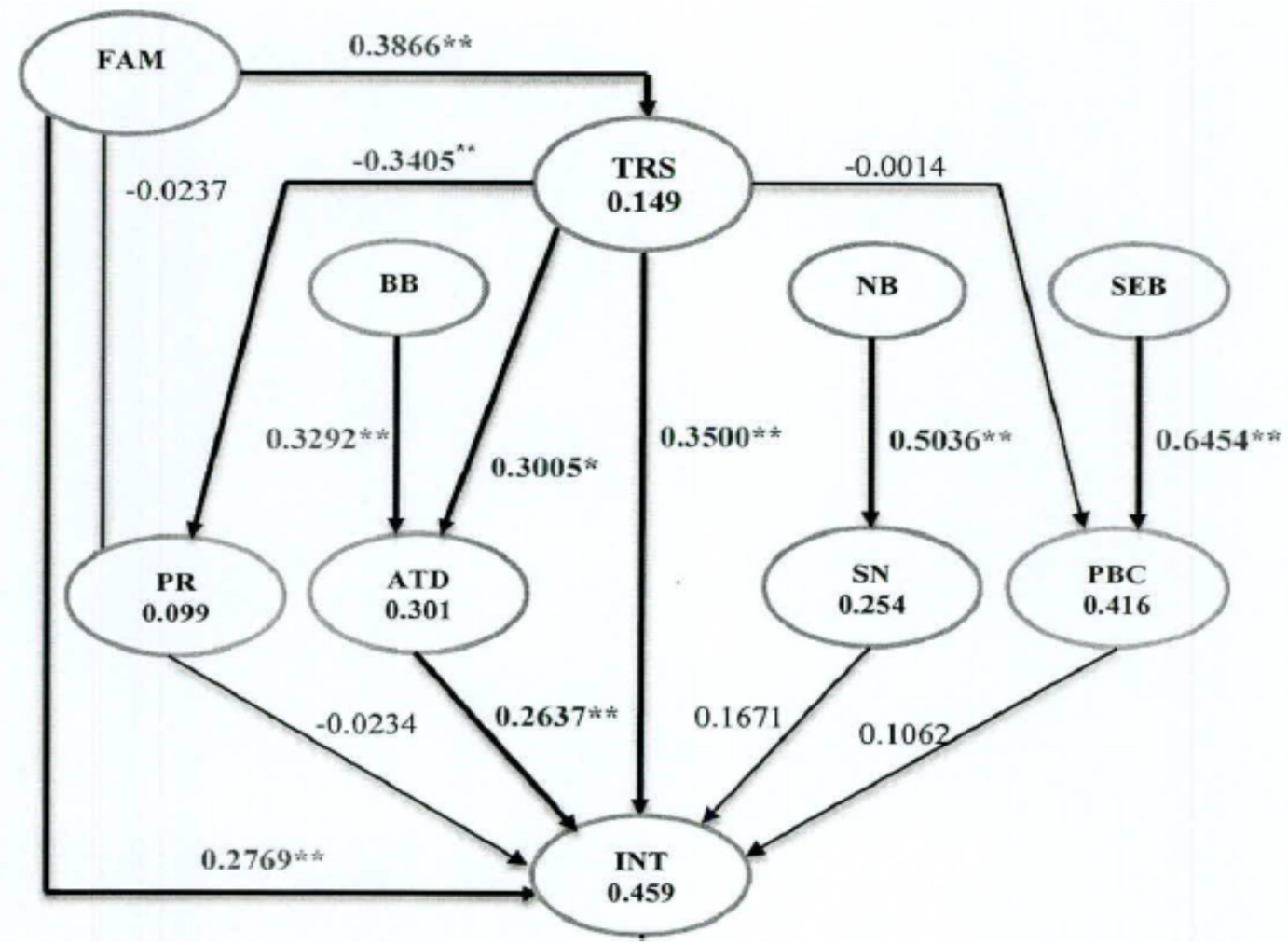

Figure 2: $\mathbf{R}^{2}$ values of the structural model 
Path coefficients between latent variables were generated by applying Smart PLS algorithm. The 'Bootstrapping' method in Smart PLS was used to generate t-values for each path coefficient (Figure 3). The 'Bootstrapping' method in Smart PLS generates path coefficients in two ways. First, it generates path coefficient only for 'hypothesized relationships' between the latent variables; and second, it generates path coefficient for 'Total Effect', for all possible relationships among latent variables. Accordingly, all interpretations given here are based on 'Total Effect' of 'Bootstrapping' method in Smart PLS. According to 'Total Effect' path coefficients from FAM to TRS $(B=0.3866, p<0.001)$ as well as FAM to INT $(B=0.2769, p<0.05)$ were significant. Similarly, path coefficients generated for TRS to INT $(B=0.3500, p<0.01)$, TRS to PR $(B=-0.3405, p<0.01)$ TRS to ATD $(B=0.3005, p<0.05)$ and ATD to INT $(B=0.2637, p<0.05)$ were also significant. These results suggest the appropriateness of the structural model to predict the intention to perform online transactions particularly in Sri Lankan context.

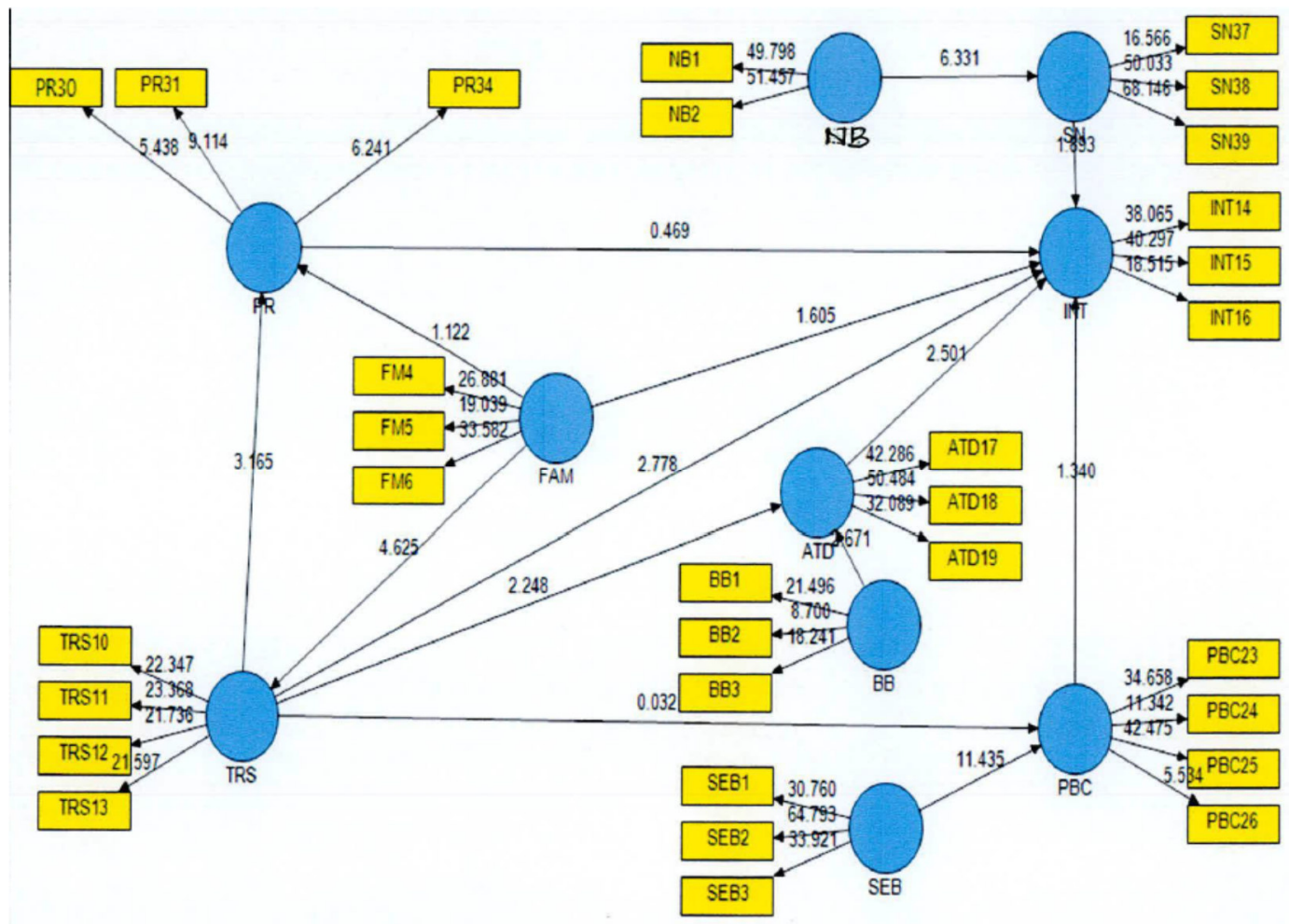

Figure 3: Smart PLS Graph Bootstrapping

\subsection{Hypothesis Testing}

The proposed hypotheses of the study were also examined with Smart PLS. PLS allows the specification of the relationship among the principal constructs as well as with their underlying items (Chin, 1998). It also facilitates the analysis of whether the hypothesized relationships at theoretical level are empirically acceptable and also how well the measures relate to each construct in the model (Chin, 1998). Table 3 presents the results of the structural model with the standardized path coefficient between latent variables.

3.9.1 Relationship between Familiarity and Trust

According to Table 3, Familiarity has positive and significant effects on consumer Trust $(\mathrm{B}=0.387, \mathrm{p}<0.001)$. Therefore, $\mathrm{H}_{1 \mathrm{a}}$ is accepted. It confirms that the Familiarity is a precondition for trust (Luhmann, 1979 cited in Gefen, 2000). This result is also consistent with the findings of Gefen (2000), Gefen, Karahanna and Straub (2003) and Kim, Ferrin and Rao (2008) who found that Familiarity has a positive and significant effect on Consumer Trust. In the context of present research, a justifiable reason may be explained as below. If Professionals who Enrolled with Postgraduate Studies (PEPS) are more familiar with web retailer's offering, which should cause them to develop concrete and favorable ideas of what to expect in the future, then they judge web retailer as more trustworthy (Kim, Ferrin and Rao, 2008). In the context of online transactions, customer familiarity relates to the understanding of web retailer's current actions while trust deals with beliefs about web retailer's future action (Gefen, Karahanna and Straub, 2003). That means, understanding of web retailer's current action (Familiarity) has a positive and significant effect on "PEPS" beliefs about web retailer's future action (Trust). 
Table 3: Summary of Hypotheses Testing

\begin{tabular}{|c|c|c|c|c|}
\hline Hypothesis & Relationship & Path coefficient & t-Value & Remark \\
\hline $\mathrm{H}_{1 \mathrm{a}}$ & Familiarity to Consumer Trust*** & 0.387 & 4.625 & Accepted \\
\hline $\mathrm{H}_{1 \mathrm{~b}}$ & Familiarity to Consumer Intention* & 0.277 & 2.569 & Accepted \\
\hline $\mathrm{H}_{1 \mathrm{c}}$ & Familiarity to Consumer Perceived Risk & -0.024 & 0.175 & Rejected \\
\hline $\mathrm{H}_{2 \mathrm{a}}$ & Trust to consumer Perceived Risk** & -0.341 & 3.126 & Accepted \\
\hline $\mathrm{H}_{2 \mathrm{~b}}$ & Trust to consumer Attitude* & 0.301 & 2.230 & Accepted \\
\hline $\mathrm{H}_{2 \mathrm{c}}$ & Trust to consumer Intention** & 0.350 & 3.623 & Accepted \\
\hline $\mathrm{H}_{2 \mathrm{~d}}$ & Trust to Perceived Behaviour Control & 0.001 & 0.019 & Rejected \\
\hline $\mathrm{H}_{3}$ & Perceived Risk to Intention & -0.023 & 0.284 & Rejected \\
\hline $\mathrm{H}_{4}$ & Behavioural Belief to Attitude** & 0.329 & 2.644 & Accepted \\
\hline $\mathrm{H}_{5}$ & Attitude to Intention* & 0.264 & 2.501 & Accepted \\
\hline $\mathrm{H}_{6}$ & Normative belief to Subjective norm $* * *$ & 0.504 & 6.331 & Accepted \\
\hline $\mathrm{H}_{7}$ & Subjective norm to Intention & 0.167 & 1.802 & Rejected \\
\hline $\mathrm{H}_{8}$ & Self-efficacy belief to $\mathrm{PBC}^{* * *}$ & 0.645 & 11.435 & Accepted \\
\hline $\mathrm{H}_{9}$ & Perceived Behaviour Control to Intention & 0.106 & 1.185 & Rejected \\
\hline
\end{tabular}

Note: ${ }^{*}$ Significant at 0.05 level, ${ }^{* *}$ Significant at 0.01 level ${ }^{* * *}$ Significant at 0.001 level

3.9.2 Relationship between Familiarity and Consumer Intention

The findings shown in Table 3 reveals that the relationship between Familiarity and Consumer Intention is positive and significant $(\mathrm{B}=0.277, \mathrm{p}<0.05)$. Therefore, $\mathrm{H}_{1 \mathrm{~b}}$ is accepted. It supports the fact that Familiarity with web retailer and its transactional procedure affects willingness to engage online transaction (Gefen, 2000). This finding is also consistent with the findings of Gefen, Karahanna and Straub (2003) and Kim, Ferrin and Rao (2008). In relation to the present study, it was evident that "PEPS" had significant experience in the usage of the Internet. Thus, it can be presumed that their computer literacy is at a higher level. Previous literature indicates that when people are more computer literate, they are more likely to engage in online transactions (Liao and Cheung, 2000). Finally, in line with the arguments of Gefen (2000) and Liao and Cheung (2000), it can be asserted that computer literacy which helped to gain familiarity with web retailer and their transactional procedure have significantly influenced 'PEPS' intention to engage online transaction.

3.9.3 Relationship between Familiarity and Perceived Risk

As expected, it is apparent that the relationship between Familiarity and Perceived Risk is negative $(B=-0.024$, $\mathrm{t}=0$. 1747). However, since this relationship is not significant, $\mathrm{H}_{1 \mathrm{c}}$ is rejected. Anyway, this result is also consistent with the findings of Kim, Ferrin and Rao (2008). As asserted by Kim, Ferrin and Ran (2008), one possible reason for this non-significant effect on perceived risk is that familiarity by its nature deals with complexity or uncertainty related to web retailer's behavioural action (i.e. web retailer's opportunistic behaviour). However, it doesn't deal with presence of environmental risk such as system risk (network speed and connectivity risk), economic risk (possible monetary losses) or privacy risk (theft of credit card information or breaches of private information by hackers). Since familiarity deals only partly with overall uncertainty, its antecedent effect on perceived risk can be non-significant.

\subsubsection{Relationship between Trust and Perceived Risk}

According to the results in Table 3, as proposed, Trust has a negative and significant effect on Perceived Risk $(B=$ - 0.341, $\mathrm{p}<0.01$ ). Consequently, $\mathrm{H}_{2 \mathrm{a}}$ is accepted. The studies undertaken by Jarvenpaa et al. (2000), Kimery and McCord (2002), Pavlou (2003), Pavlou and Gefen (2004), Thomson and Liu (2007) and Kim, Ferrin and Rao (2008) also found that trust reduces risk. Therefore, the result of the present study is consistent with the findings of many previous researchers. Perceived risk can be related to both the reliability of the vendor and reliability of communications made over the Internet. However, fulfilment of requirements of a customer by a web retailer increases the trust towards that web retailer. It can be inferred that "PEPS" do online transactions with web sites with which they are more familiar with and which fulfill their requirements in a satisfactory manner. Accordingly, as the trust towards the web sites increases, the perceived risk of those web sites go down.

3.9.5 Relationship between Trust and Attitude

Results reveal (see Table 3 ) that Trust has a positive and significant effect on Attitude $(\mathrm{B}=0.301, \mathrm{p}<0.05)$. Consequently, $\mathrm{H}_{2 b}$ is accepted. The significant relationship between Trust and Attitude is consistent with findings of Jarvenpaa et al. (2000), Kimery and McCord (2002), Pavlou and Chai, (2002), Suh and Han (2003), George (2004) and Thomson and Liu (2007). Trust towards a website may be increased by addressing customers' concerns related to areas such as privacy protection, unauthorized access, secured communications and so on. It is apparent that for "PEPS", as the trust increases, attitude towards the website has become more positive and favourable.

3.9.6 Relationship between Trust and Consumer Intention

According to Table 3, Trust has a positive and significant effect on Consumer Intention $(\mathrm{B}=0.350, \mathrm{p}<0.01)$. Therefore, $\mathrm{H}_{2 c}$ is accepted. Findings of this study is consistent with the findings of Pavlou (2003), Gefen, 
Karahanna and Straub (2003). Suh and Han (2003), Thomson and Liu (2007) and Kim, Ferrin and Rao (2008). Results reveal that for "PEPS" trust of the web retailer is a major factor influencing the purchase decision. Trust has been confirmed as an antecedent to consumer purchase intention. Therefore, for "PEPS", as their trust towards the web retailer increases, their intention to purchase from that retailer increases.

\subsubsection{Relationship between Trust and Perceived Behaviour Control}

Table 3 reveals that the relationship between Trust and Perceived Behaviour Control is not significant $(B=0.001$, $\mathrm{t}=0.0193$ ). Hence $\mathrm{H}_{2 \mathrm{~d}}$ is rejected. This finding is consistent with the findings of Fang, Shao, \& Lan. (2009). PBC is a complicated construct (Fang et al., 2009) focusing on two dimensions: self-efficacy and controllability. Nonsignificant relationship found between trust and $\mathrm{PBC}$ could be due to the fact the present questionnaire captures more on the "controllability" aspect of "PEPS", but lack of capturing related the self-efficacy aspect.

3.9.8 Relationship between Perceived Risk and Intention

Table 3 reveals that the relationship between Perceived Risk and Intention is negative as expected $(B=-.0237$, $\mathrm{t}=0.175)$. However, contrary to the expectations, this relationship is not significant and hence, $\mathrm{H}_{3}$ is not supported. This finding is consistent with the findings of Abu-Shanab and Ghaleb (2012) and Gurung and Raja (2016). Purchase intention is influenced not only by perceived risk, but also by trust beliefs towards the web retailer (Gurung and Raja, 2016). As discussed above, it could be noticed that there is a significant relationship between trust and purchase intention. Consequently, as "PEPS" pay a greater weight to trust factor, they may pay a lower weight to the perceived risk factor.

\subsubsection{Relationship between Behavioural Belief and Attitude}

Behavioural Belief was predicted as an antecedent to Attitude. Results confirm (see Table 3) that Behavioural Belief has a positive and significant effect on Attitude $(B=0.329, p<0.01)$. Hence, $\mathrm{H}_{4}$ is accepted. This is consistent with the findings of Kim, Kim, Choi, \& Ham, (2018). Thus, it is apparent that "PEPS" individual beliefs significantly influence their attitude towards purchase intention. This is a confirmation that behavioural belief is an antecedent to attitudes of individuals (Ajzen, 1991).

3.9.10 Relationship between Attitude and Intention

As revealed in Table 3 and as proposed, there is a positive and significant relationship between Attitude and Customer Intention $(\mathrm{B}=0.264, \mathrm{p}<0.05)$. Therefore, $\mathrm{H}_{5}$ is also accepted. This finding is consistent with the findings of many other researchers including Nam, Dong, \& Lee., (2017); Giampietria at al. (2018); and Rehman, Bhatti, Mohamed, \& Ayoup (2019). Results reveal that positive attitude of "PEPS" towards online shopping will result in increasing the intention to purchase online. It is apparent that factors such as convenience in getting information and purchasing, and saving of time etc. help develop a positive attitude towards online purchasing among "PEPS". This is in line of the argument that attitude is a major determinant of intention (Ajjen, 1991).

3.9.11 Relationship between Normative Belief and Subjective Norm

Results reveal (see Table 3) that Normative Belief has a positive and significant relationship with Subjective Norm $(\mathrm{B}=0.504, \mathrm{p}<0.001)$. Accordingly, $\mathrm{H}_{6}$ is accepted. This is in line with prior research on online transaction conducted by Bhattacherjee (2000) and George (2004). This illustrates that "PEPS" are influenced by others in their beliefs towards online purchasing decisions. This can be quite understandable, since the respondents are from the working community and hence their behaviour can be extensively influenced by their colleagues.

3.9.12 Relationship between Subjective Norm and Intention

As per Table 3, it is revealed that the relationship between Subjective Norm and Consumer Intention is not significant $(\mathrm{B}=0.167, \mathrm{t}=1.802)$. Consequently, $\mathrm{H}_{7}$ was not supported. However, this finding is consistent with the findings of Chai and Pavlou (2004); Wu and Chen (2005); Lin (2006); and Pavlou and Fygenson (2006). The nonsignificant finding can be due to several reasons as illustrated below. The effect of subjective norm can differ on whether the behaviour change is mandatory or voluntary. When the change is mandatory, the subjective norm has a significant effect on intention, but when the change is voluntary, the subjective norm does not have a significant effect on intention (Venkatesh and Davis, 2000). In the present context, online purchasing is a voluntary decision for the "PEPS". Further, "PEPS" have adequate exposure to the Internet and also possess required knowledge and skill to make their own decisions, rather than being influenced by others (Lin, 2006).

3.9.13 Relationship between Self-efficacy Belief and Perceived Behaviour Control

According to Table 3, and as predicted, Self-efficacy Belief has a positive and significant effect on Consumer Intention $(\mathrm{B}=0.645, \mathrm{p}<0.001)$. Hence, $\mathrm{H}_{8}$ is supported and accepted. This is in line with prior research on online transaction conducted by Bhattacherjee (2000); George (2004); Alam. and Sayuti (2011); and Nasri and Charfeddine (2018). This confirms the fact that self-efficacy is a determinant of PBC (Ajzen, 1991). For "PEPS", their ability and confidence of using the Internet tend to influence positively to their behaviour changes towards online purchasing.

3.9.14 Relationship between Perceived Behaviour Control and Intention

As per the findings shown in Table 3, it is apparent that the relationship between Perceived Behaviour Control and Consumer Intention is not significant $(\mathrm{B}=0.106, \mathrm{t}=1.1845)$. Accordingly, $\mathrm{H}_{9}$ is rejected. This finding is consistent with the finding of Chai and Pavlou (2004) and Nam, Dong, and Lee (2017). There can be several reasons behind 
the non-significant relationship found here. The effect of $\mathrm{PCB}$ on intention may depend upon extent to which individuals try to avoid uncertainty. In a culture where there is high uncertainty avoidance, PBC tend to have a significant effect on intention to purchase where there is low uncertainty avoidance, $\mathrm{PBC}$ seem to have no significant effect on intention to purchase (Chai and Pavlou, 2004). The Sri Lankan culture, where "PEPS" are part of it, can also be considered as a culture having low uncertainty avoidance. Further, measurement of PBC mainly focused on possession of knowledge, resources, and capabilities. There can be other factors influencing PBC towards purchase intention (Nam et al., 2017).

\section{Theoretical and practical implications}

The researchers introduced an improved model to original TPB mode by adding three important variables: familiarity, trust, and perceived risk. This model demonstrated to be effective in predicting consumer intention for online shopping. Amongst those new variables, familiarity and trust were found to have significant effects on consumer's online purchase intention. Other than those two variables, attitude was also identified as a key determinant of consumer intention. Further, when examining the overall impact of the model, trust has the highest impact on consumer intention. These findings lead to several practical implications.

Sri Lanka can be still considered to be in an early stage of transformation from offline to online transactions. Since trust has been found as a critical factor influencing the customer intension towards online shopping, web retailers may need to stress the integrity, security and reliability of their transactions to build trust towards their business. Measures such as assurances given on privacy protection, use of a secured payment method, and use of trust and security seals offered by third parties can be used.

Development of a favourable and positive attitude towards web retailers is important to increase the attraction of customers to their web sites and also to increase online transactions. In this regard, web retailers can emphasize on areas such as ease of use, convenience, usefulness, trust, offering recommendations, personalization of the website and so on.

There were several limitations to this study as well. First, this study used postgraduate students and convenient sampling method. This can cause some issues in generalizing the results to the population of online consumers. Future research can focus on a sample which can better reflect the total population. Second, this study examined social and behavioural measures influencing the consumer intention. Future research can focus on incorporating other factors related to areas such as technology, infrastructure, culture and so on affecting the consumers' intention to purchase online. Third, demographic factors such as age, income, education etc. may also have an impact on the intention to use online shopping. Hence, future researchers can compare between different such groups to see whether the purchase intention differs among different demographic groups.

\section{References}

Abu-Shanab, E. \& Ghaleb, O. (2012). Adoption of Mobile Commerce Technology: An Involvement of Trust and Risk Concerns, International Journal of Technology Diffusion, 3(2), 36-49, DOI: 10.4018/jtd.2012040104

Ajzen I. (1985) From Intentions to Actions: A Theory of Planned Behaviour. In: Kuhl J., Beckmann J. (eds) Action Control. SSSP Springer Series in Social Psychology. Springer, Berlin, Heidelberg.

Ajzen, I. (1991) The theory of planned behaviour. Organizational Behaviour and Human Decision Processes, 50 , 179-211.

Ajzen, I., and Fishbein, M. (1980). Understanding attitudes and predicting social behaviour. London: Englewood Cliffs, Prentice-Hall.

Alam, S.S. \& Sayuti, N.M., (2011). Applying the Theory of Planned Behaviour (TPB) in halal food purchasing, International Journal of Commerce and Management, 21 (1), 8 - 20, DOI:10.1108/10569211111111676

Asia Briefing. (2014). E-Commerce Across Asia: Trends and Developments, May 2014, 4-6. Available: https://www.asiabriefing.com/news/2014/05/e-commerce-across-asia-trends-developments-2014-newissue-asia-briefing-magazine-2/

Battacherjee, A. (2000). Acceptance of c-commerce services: the case of electronic brokerages. IEEE Transactions on Systems, Man, and Cybernetics - Part A: Systems and Humans, 30(4), 411 - 420.

Central Bank of Sri Lanka. (2012). Annual report 2012 (Online). Available: <liitp://wvw.cbsl.gov.lk/pics_n_docs/10_pub/_docs/efr/annual_report/AR2012/English/content.htm/>.

Chai, L. and Pavlou, P.A. (2004). From "ancient" to "modern": a cross-cultural investigation of electronic commerce adoption in Greece and the United States, The Journal of Enterprise Information Management, 17(6). 416-423, DOI: 10.1108/17410390410566706

Chellappa, R.K. and Pavlou, P.A. (2002). Perceived information security, financial liability and consumer trust in electronic commerce transactions. Journal of Logistics Information Management, 15(5/6), 358-368.

Chen, Y.H. and Barnes, S. (2007). Initial trust and online buyer Behaviour. Industrial Management \& Data Systems, 107(1), 21-36.

Chin, W.W. (1998). Issues and Opinion on Structural Equation Modeling, MIS Quarterly, 22(1), 7-16. 
DailyNews. (2018). Sri Lanka's e-commerce segment records 34\% growth (Published on 26.11.2018).

Dennis, C., Merrilees, B., Jayawardhena, C. and Wright, L.T. (2008). E-consumer behaviour. European Journal of Marketing, 43(9/10), 1121-1139.

Davis, F. D., Bagozzi, R. P., \& Warshaw, P. R. (1989). User Acceptance of Computer Technology: A Comparison of Two Theoretical Models, Management Science; 35(8), 982-1003

Davis, F.D. (1989). Perceived Usefulness, Perceived Ease of Use, and User Acceptance of Information Technology, MIS Quarterly, 13(3), 319-340

Economynext. (2019). Sri Lanka e-commerce use still low, survey finds (Published on 23.05.2019), Available: https://economynext.com/sri-lanka-e-commerce-use-still-low-survey-finds-14160/

Fang, J., Shao, P., \& Lan, G., (2009). Fang, J., Shao, P., \& Lan, G., (2009). Effects of innovativeness and trust on web survey participation, Computers in Human Behaviour, 25(1), 144-152, DOI: 10.1016/j.chb.2008.08.002

Fornell, C. and Larcker, D.F. (1981). Evaluating Structural Equation Models with Unobservable Variables and Measurement Error, Journal of Marketing Research, 18(1), 39-50, DOI: 10.2307/3151312.

Forrester Research. (2013). US Online Retail Sales to Reach S370 Billion by 2017 (Online). Available at: http://www.forrester.com/US+Online+Retail+Sales+To+Reach+370+Billion+By+2017/-/E-PRE4764.

Gefen, D. (2000). E-commerce: The role of familiarity and trust, Omega: The International Journal of Management Science, 28(6), 725-737.

Gefen. D., Karahanna. E. and Straub, D.W. (2003). Inexperience and Experience with Online Stores: The Importance of TAM and Trust. IEEE Transactions on Engineering Management, 50(3), 307-321.

George, J.F. (2004). The theory of planned behaviour and internet purchasing. Internet Research, 14(3), $198-212$.

Giampietria, E., Verneaub, F., Giudicec, T.D., Carforad, V., \& Fincoa, A. (2018). A Theory of Planned behaviour perspective for investigating the role of trust in consumer purchasing decision related to short food supply chains. Food Quality and Preference, 64, 160-166, DOI: 10.1016/j.foodqual.2017.09.012

Gurung, A. and Raja, M. (2016). "Online privacy and security concerns of consumers", Information and Computer Security, 24(4), 348-371. DOI:10.1108/ICS-05-2015-0020

Hathiramani, J. (2013). Sri Lanka online search up as much as 25 times. (Published on Sunday Times on 26. 05. 2013). Available: http://www.sundaytimes.lk/130526/business-times/sri-lanka-online-search-up-as-muchas-25-times-google-45632.html

Heijden, H., Verhagen, T. and Creemers, M. (2003). Understanding online purchase intention: Contribution from technology and trust perspectives. European journal of information systems, 12(1), 41-48.

Kwon, W.S. (2000). The influence of prior experience and age on mature consumers' perceptions and intentions of internet apparel shopping. Journal of Fashion Marketing and Management, 14 (3), 335-349.

Jarvenpaa, S.L. and Todd, P.A. (1997). Consumer Reactions to Electronic Shopping on the World Wide Web, Journal of Electronic Commerce, 1(2): 59-88,

Jarvenpaa, S.L., Tractinsky, N., \& Saarinen, L. (1999). Consumer trust in an Internet store: A cross-cultural validation. Journal of Computer-Mediated Communication, 5(2), DOI: 10.1111/j.1083-6101.1999.tb00337.x

Jarvenpaa, S. L., Tractinsky, N. and Vitale, M. (2000). Consumer Trust in an Internet Store. Information Technology and Management, 1(12), 45-71.

Kamarulzaman, Y. (2007), "Adoption of travel e - shopping in the UK", International Journal of Retail \& Distribution Management, 35(9), 703-719. DOI: 10.1108/09590550710773255

Khalifa, M. and Limayem, M. (2003), "Drivers of Internet shopping”, Communications of the ACM, 46(12), 233239.

Kim, D.J., Ferrin, D.L. and Rao, R.H. (2008). A trust-based consumer decision-making model in electronic commerce: The role of trust, perceived risk, and their antecedents. Decision Support Systems, 44(2), 544-564.

Kim, H., Kim, Y., Choi, H. \& Ham, S. (2018). Relationships among behavioural beliefs, past behaviours, attitudes and behavioural intentions toward healthy menu selection. Nutrition Research and Practice, 12(4), 348-354

Kimery, K.M. and MacCord, M. (2002). Third-Party Assurances: The Road to Trust in Online Retailing, Proceedings of the $35^{\text {th }}$ Hawaii International Conference on System Sciences -2002.

LBO. (2017), E-commerce shakes up Sri Lanka's retail sector, Available: https://www.lankabusinessonline.com/interview-e-commerce-shakes-up-sri-lankas-retail-sector-says-takasceo/

Lee, M.C., (2009). Factors influencing the adoption of internet banking: An integration of TAM and TPB with perceived risk and perceived benefit. Electronic Commerce Research and Applications, 8(3), 130-141

Liao, Z. and Cheung, M.T. (2000). Internet-based e-shopping and consumer attitudes: an empirical study. Information \& Management 38, pp.299-306.

Li, H., Kuo, C. and Russell, M.G. (1999). The impact of perceived channel utilities, shopping orientations, and demographics on the consumer's online buying behaviour. Journal of Computer-Mediated Communication, 5(2), (Wiley Online Library), DOI: 10.1111/j.1083-6101.1999.tb00336.x.

Lin, H., (2006). Understanding Behavioural Intention to Participate in Virtual Communities, Cyberpsychology \& 
Behaviour, 9(5), 540-547

Malhotra. N.K. and Dash, S. (2000). Marketing Research: an applied orientation. Dorling Kindersley (India) Pvt Ltd.

McKnight, D.H. and Chervany, N.L. (2002). What trust means in e-commerce customer relationships: An interdisciplinary conceptual typology. International Journal of Electronic Commerce, 6(2), pp.35-60.

Mostafa, R. and Elseidi, R. (2018). Factors affecting consumers' willingness to buy private label brands (PLBs), Spanish Journal of Marketing - ESIC, 22(3), 338-358. DOI: 10.1108/SJME-07-2018-0034

Nam, C., Dong, H. \& Lee, Y. (2017). Factors influencing consumers' purchase intention of green sportswear, Fashion and Textiles, 4(2), 1-17

Nasri, W. \& Charfeddine, L. (2018). Factors affecting the adoption of Internet banking in Tunisia: An integration theory of acceptance model and theory of planned behaviour, Food Quality and Preference, 64, 160-166, DOI: $10.1016 /$ j.foodqual.2017.09.012

Olson, J.S. and Olson, G.M. (2000). i2i Trust in E-commerce, Communications of the ACM, 43(12), 41-44

Oxley, J.E. and Yeung, B. 2001. E-Commerce Readiness: Institutional Environment and International Competitiveness. Journal of International Business Studies, 32(4) 705-723.

Pavlou, P.A. (2003). Consumer Acceptance of Electronic Commerce - Integrating Trust and Risk with the Technology Acceptance Model. International Journal of Electronic Commerce, 7(2), 72-88.

Pavlou, P.A. and Chai, L. (2002). What Drives Electronic Commerce Across Cultures? A Cross-Cultural Empirical Investigation of the Theory of Planned Behaviour. Journal of Electronic Commerce Research, 3(4), $240-253$.

Pavlou, P.A. and Gefen D. (2004). Building effective online marketplaces with institution-based trust. Information Systems Research, 15(1), 37-59.

Pavlou, P.A. and Fygenson, M. (2006). Understanding and Predicting Electronic Commerce Adoption: An Extension of the Theory of Planned Behaviour, MIS Quarterly, 30 (1), 115-143, DOI: 10.2307/25148720

Rehman, S., Bhatti, A., Mohamed, R., \& Ayoup, H. (2019). The moderating role of trust and commitment between consumer purchase intention and online shopping behaviour in the context of Pakistan, Journal of Global Entrepreneurship Research, 9(1), 1-25, DOI: 10.1186/s40497-019-0166-2

Roca, J.C., Garcia, J.J. and Vega, J.J., 2009. The importance of perceived trust, security and privacy in online trading systems. Information Management \& Computer Security, 17(2), 96-113.

Suh, B. and Han, I. (2003). The impact of customer trust and perception of security control on the acceptance of electronic commerce. International Journal of Electronic Commerce, 7(3), 135-161.

Taylor, S. and Todd, P.A. (1995). Understanding information technology usage: a test of competing models. Information Systems Research, 6(2), 144-76.

Thompson, S.H.T. and Liu, J. (2007). Consumer trust in e-commerce in the United States, Singapore and China. The International Journal of Management Science, Omega 35, 22-38.

Venkatesh, V. \& Davis, F.D. (2000) A Theoretical Extension of the Technology Acceptance Model: Four Longitudinal Field Studies. Management Science, 46(2), 186-204., DOI: 10.1287/mnsc.46.2.186.11926

Wen, I. (2009). Factors affecting the online travel buying decision: a review, International Journal of Contemporary Hospitality Management, 21(6), 752-765. DOI: 10.1108/09596110910975990

Wu, I \& Chen, J. (2005). An extension of Trust and TAM model with TPB in the initial adoption of on-line tax: An empirical study, International Journal of Human-Computer Studies, 62(6), 784-808, DOI: 10.1016/j.ijhcs.2005.03.003 